\title{
Educational Program for Pregnant Women Regarding Obstetrics Dangerous Signs in Rural Areas
} \author{
M. Mahmoud Rabeh", Rofida M. Elshafei, Almandouh Hussein Bosilah6, \\ Hala Hassan Saied Khalil', Sharbat Thabet Hassanine ${ }^{6}$, Manal Mansour Mostafa7, \\ Mohamed Sobhy Bakry7, Safaa A. Ibrahim³, Eman Ramadan Abd El Fattah², \\ Abeer M. Abdelbary ${ }^{1}$ \\ ${ }^{1}$ Pathology, Faculty of Medicine, Zagazig University, Zagazig, Egypt \\ ${ }^{2}$ Anatomy, Faculty of Medicine, Zagazig University, Zagazig, Egypt \\ ${ }^{3}$ Obstetrics \& Gynecology, Faculty of Medicine, Zagazig University, Zagazig, Egypt \\ ${ }^{4}$ Zoology (Physiology) Department, Faculty of Science, Zagazig University, Zagazig, Egypt \\ ${ }^{5}$ Stem Sharqiai, Zagazig, Egypt \\ ${ }^{6}$ Nursing, Faculty of Medicine, Fayoum University, Fayoum, Egypt \\ ${ }^{7}$ Obstetrics \& Gynecology Faculty of Medicine, Fayoum University, Fayoum, Egypt \\ Email: magibran@medicine.zu.edu.eg
}

Mai Ahmed Gobran1, Marwa Tharwat Abdel Fatah², Mohamed S. H. Ramadan³, Ghada A. Amer4,

How to cite this paper: Gobran, M.A., Fatah, M.T.A., Ramadan, M.S.H., Amer, G.A., Rabeh, M.M., Elshafei, R.M., Bosilah, A.H., Khalil, H.H.S., Hassanine, S.T., Mostafa, M.M., Bakry, M.S., Ibrahim, S.A., El Fattah, E.R.A. and Abdelbary, A.M. (2021) Educational Program for Pregnant Women Regarding Obstetrics Dangerous Signs in Rural Areas. Open Journal of Obstetrics and Gynecology, 11, 529-552.

https://doi.org/10.4236/ojog.2021.115050

Received: January 30, 2021

Accepted: May 16, 2021

Published: May 19, 2021

Copyright $\odot 2021$ by author(s) and Scientific Research Publishing Inc. This work is licensed under the Creative Commons Attribution International License (CC BY 4.0).

http://creativecommons.org/licenses/by/4.0/

\begin{abstract}
Background: Complications linked to postpartum \& pregnancy are one of the major causes of female death. In order to understand the causes of complications and encourage women to take sufficient action in order to receive emergency treatment, a critical step should therefore be taken to minimize complications related to pregnancy, in order to ensure the safety of both women and newborns. Aim of the work: Evaluate the effectiveness of the education programs for pregnant women on obstetric danger signs in rural areas and help minimize the incidence of pregnancy loss and comorbidities. Methods: A quasi-experimental design on 70 women from a population of through 372 women in six-month in antenatal clinics recruited from the previously mentioned settings with pre- and post-test was conducted at antenatal clinics (M.C.H centers) affiliated to the available geographical health zones in EL-fayoum rural area including: Al-sheikh hassan at sanorse. We collected the data of women characteristics by a self-administered interview questionnaire \& a structured reported knowledge and practices checklist to evaluate pregnant women practices and knowledge. Follow up was done to the studied groups \& histopathology assessments of the product of conception in cases of abortion secondary to the complications to compare between effect of ante-
\end{abstract}


natal care program on the woman who followed the program and those who did not. Results: There is an improvement in $63 \%$ of pregnant women knowledge and practices after educational program in all aspects. The most common danger signs that may occur during pregnancy were miscarriage and vaginal bleeding, intrauterine fetal death as reported by women \& confirmed by the histopathology reports. Conclusion: The educational program had an efficient improving women knowledge and practice regarding danger signs for pregnant women in rural areas, with highly statically significant differences in all the tested items between pre/post program implementation $(\mathrm{P}<0.001)$. Recommendations: Establishment of in-service training programs and continuous supervision in rural areas to a raise women knowledge and practice regarding educational pregnant women and developing antenatal classes for all pregnant women about obstetric danger signs.

\section{Keywords}

Obstetric Danger Signs, Knowledge, Practice, Obstetric Complications

\section{Introduction}

Women worldwide get pregnant, and about $10 \%$ of them will potentially develop complications that will demand experienced/skilled obstetric care to avert death or life-threatening problems. It has also been attested that every day about 14,000 women lose their lives as a result of complications from pregnancy and childbirth. In many developing nations including Ethiopia, maternal mortality yet remains a significant burden and therefore change towards Millennium Development Goal (MDG) five has been particularly disregarded. In developing countries, maternal mortality ratio (MMR) is 15 times higher compared to developed countries. Africa, in particular Sub-Saharan countries suffered from the highest MMR at 500 maternal deaths per 100,000 live births [1].

A systematic analysis towards the progress of Millennium Development Goal 5 showed that more than $50 \%$ of all maternal deaths in 2008 were in only six countries (India, Nigeria, Pakistan, Afghanistan, Ethiopia, and the Democratic Republic of the Congo) [2]. The magnitude of maternal mortality and morbidity in Ethiopia are among the highest in the globe. Ethiopian demography and health survey (EDHS) reports from 2005 and 2011 showed that MMR was 673 and 676 per 100,000 live births, respectively [3].

The danger signs are not the literal obstetric complications, merely symptoms that are well named by non-clinical personnel. The most frequently occurring danger signs during pregnancy include severe vaginal bleeding, swollen hands/ face and blurred vision. The fundamental danger signs during labor and childbirth include severe vaginal bleeding, pro-longed labor, convulsions, and retained placenta. Danger signs during the postpartum period include severe bleeding following childbirth, loss of consciousness after childbirth, and fever. The identification of these danger signs and its relation with complications during 
pregnancy would increase the capacity of women, their partners and families to seek for timely health care, following the appropriate steps to insure a safe birth and post-partum [4].

Approximately $80 \%$ of maternal deaths globally occurred due to direct obstetric complications (postpartum severe bleeding, infections following delivery, unsafe induced abortion, and hypertensive disorders in pregnancy and obstructed labor). Hemorrhage solely accounts for one third of all maternal deaths in Africa; still many of these deaths are avoidable. Indirect causes such as malaria, diabetes, hepatitis, anemia and other cardiovascular disorders aggravated by pregnancy can also lead to maternal death [5].

In recent decades, numerous strategies have been carried out for the betterment of maternal health throughout the world, the basic aim of antenatal care is to identify the main symptoms and prevent the appearance of life -threatening complications during pregnancy, thus addressing the pregnant women's information needs and providing advice and reassurance.

The national reproductive strategy of Ethiopia has given stress to maternal and newborn health to cut down the increased maternal and neonatal mortality. Two of the strategies are empowering women, men, families, and communities to recognize pregnancy-related risks, and to take responsibility for developing and implementing appropriate responses to them and creating an environment supportive to safe motherhood and newborn health [1].

The Federal Ministry of Health (FMOH), reproductive health department and health bureaus of respective regions in Ethiopia have made cooperative effort to promote knowledge of women about obstetric danger signs to decrease maternal mortality to an acceptable level. They have been applying multiple approaches at local and national levels to have better access to health care information across the country including activities as training of health care providers and health extension workers, organizing civil societies, supporting women to women's associations (such as Health development army, women's networks, etc.), increasing access to health facilities and allocating health resources equitably among rural and urban areas [6].

Though, big emphasis is given by the national strategy to raise knowledge of obstetric danger signs, there is little information about the current level of knowledge and the determining factors in Ethiopia. It is important to share information with women and their families about the early detection and recognition of danger signs and complications as part of birth and emergency planning. You need to discuss with them what the danger signs are and help them to think about and decide where they will go if they experience one or any of these [7].

Pregnancy and childbirth are special events in women's life and in the lives of their families. This can be a time of great hope and joyful anticipation; it can also be a time of fear, suffering and even death. Complications of pregnancy and childbirth are often the leading causes of morbidity and mortality among women in childbearing ages in the developing countries. At least $40 \%$ of all pregnant 
women will experience some type of complications during their pregnancies. For about $15 \%$ of them, these complications will be potentially life-threatening, and will require immediate obstetric care. WHO estimated that half a million women die annually from pregnancy-related causes and that $99 \%$ of these deaths occur in developing countries In Egypt, the national maternal mortality ratio in 2011 was 57 per 100.000 births. While, during 2007-2009, it was 123.94 per 100.000 births in FAYOUM University Hospital, Egypt [8].

The direct complications that account for more than $70 \%$ of maternal deaths are hemorrhage, infection, unsafe abortion, eclampsia, and obstructed labor. While these are the main causes of maternal death; unavailable, inaccessible, unaffordable, or poor-quality care is fundamentally responsible. There are also three levels of delays that contribute to these deaths which are known as barriers in seeking emergency obstetric care when maternal complications occur. These levels are: delay in making decision to seek care, delay in arrival at a health facility, and delay in receiving adequate treatment [9].

Most maternal deaths are avoidable through well-functioning health system that provides accessible and high-quality care from household to hospital level during antenatal, natal and postnatal period. These deaths could be also prevented significantly, if women and their families recognize obstetric danger signs and promptly seek health care [10].

Obstetric danger signs include: persistent vomiting, severe abdominal pain, vaginal bleeding during pregnancy and delivery, severe vaginal bleeding after delivery, swelling of the face, fingers, or feet, blurring of vision, fits during pregnancy, severe headache, high grade fever, marked change in fetal movements, and high blood pressure. In addition, sudden escape of fluid from the vagina, dysuria, oliguria or anuria, prolonged labor, loss of consciousness, and retained placenta [5].

Antenatal care also detects and manages high-risk pregnancies early, and represents a window of opportunity for education and communication to pregnant women so that they will make appropriate choices especially when they are in danger. Moreover, natal and postnatal cares are very crucial because these periods represent the period of highest risk of death and disability for both the mother and her newborn. Information, education and counseling provided during these periods are key in management of complications as it would improve early detection of complications and reduces the delay in deciding to seek obstetric care. So, one of the most important responsibilities of the nurse is to increase knowledge and practices of the pregnant woman and her family about the potential danger signs during pregnancy, labor and delivery and during the postpartum period [11].

\section{Magnitude of the Study}

According to Egypt demography and health survey, slightly more than one-quarter of Egyptian pregnant women do not receive antenatal care. However, among 
those who receive antenatal care, only one-third of them received advices about signs of obstetric complications, and where and when to seek medical assistance. lack of knowledge of the significance for symptoms of obstetric danger signs is one of the reasons of failure to identify and seek appropriate emergency care [12].

This study therefore aims to assess the current status of educational program of pregnant women toward obstetric danger signs at rural area. In Egypt where one of every 16 women dies of pregnancy related causes during her lifetime, compared with only 1 in 2800 women in develop regions, raising awareness of women about obstetric danger signs would improve early detection of problems and help in seeking timely obstetric care [2].

Therefore, assessment of women's knowledge of obstetric danger signs and associated factors contributes for the planners and implementers to improve maternal health.

\section{Aim of the Study}

To evaluate the educational program on pregnant women knowledge and practices regarding obstetric danger signs in $\mathrm{MCH}$ centers at rural area in fayoum through

1) Assessing the women's level of knowledge regarding the danger signs of pregnancy women to detect their needs, knowledge and practices.

2) Designing and implementing training programs based on their needs.

3) Evaluating the effect of educational programs on women's knowledge and practices regarding the dangerous signs of pregnant women.

\subsection{Research Hypotheses}

- The educational program will improve the women level of knowledge and practices about obstetric danger signs during pregnancy and childbirth.

\subsection{Subjects and Methods}

Research Design:

A quasi-experimental design with pre and post-test was used to accomplish the aim of the study.

Setting:

The study was conducted at antenatal care clinics in maternal child health centers in village El-Shakh Hassan at sanours belonging to fayoum governorate, Egypt. Affiliated to the Ministry of Health, it covers rural district and has a high flow rate of pregnant women. It contains 2 flowers contained in the first floor clinic (antennal care, dental, immunization, medicine) and second floors contain a pediatric clinic, delivery operation, laboratory room, and patient room). The antenatal clinic three days per week (Sunday-Tuesday-Thursday).

Subjects:

A none probability convenience sample 70 pregnant women attending the 
antenatal clinics from one previously mentioned setting to be included in this study from total 372 women attending $\mathrm{MCH}$ during period 6 month. To their criteria

The subjects of this study were selected according to the following inclusion criteria:

- Pregnant women with gestational age of at least 8 weeks gestation.

- Primigravida and/or multigravida.

- Pregnant women with normal current pregnancy course.

- Aged 18 - 35 years.

Exclusion criteria:

- Women not willing to participate in the study

- Women not pregnant and oldest 40 years

Tools for data collection:

Two tools were utilized to gather the required information and consumed around four months.

A specially-designed structured interview schedule sheet was constructed based on the recent review of literatures to collect the required data regarding the study elements. The interview schedule sheet covered the following parts:

Part one: It assessed the socio-demographic characteristics of women such as: age, residence, level of education, and occupation.

Part two: It included questions related to history of obstetric of women such as; gravidity, parity, number of abortions, presence of obstetrical complications in previous pregnancies, deliveries and puerperium, mode and place of last delivery, time, place of antenatal care, and number of antenatal visits.

Part three: This part assessed women's knowledge about danger signs of obstetric complications. It included 14 questions about: danger signs that may occur during pregnancy, labor and postpartum period, obstetric complications that may occur during pregnancy, delivery and puerperium; whether danger signs are different from obstetric complications, and the women's sources of knowledge about danger signs.

The scoring system regarding women's knowledge was as follow:

- Women who mentioned more than two danger signs of pregnancy, of childbirth and of postpartum period = good knowledge (was given score 2).

- Women who mentioned two danger signs of pregnancy, of childbirth and of postpartum period = fair knowledge (was given score 1).

- Women who mentioned one danger sign during pregnancy, childbirth or postpartum period or not mentioned any danger signs at all and/or don't know $=$ poor knowledge (was given score zero).

The total knowledge score level calculated by (13 questions $\times 2=26$ ) which categorized was as follows:

1) Good level of knowledge $>75 \%=(>20$ scores $)$.

2) Fair level of knowledge $50 \%-<75 \%=(13-<20$ scores $)$.

3) Poor level of knowledge $<50 \%=(<13$ scores $)$.

Part four: This part related to women's practices toward danger signs of ob- 
stetric complications that may occur during pregnancy, labor and postpartum period. It included questions about: practices performed by pregnant women to overcome danger signs, anticipated practices and/or measures that may be taken by women regarding any aroused danger signs during labor \& delivery and during postpartum period.

The total practice score level calculated by (13 questions $\times 2=26$ ) which categorized was as follows:

1) Good level of practices $>75 \%=(>20$ scores $)$.

2) Fair level of practices $50 \%-<75 \%=(13-<20$ scores $)$.

3) Poor level of practices $<50 \%=(<13$ scores $)$.

${ }^{\star}$ Follow up was done to the studied group and histopathology assessments of the Product of conception in cases of abortion secondary to the complications to compare between effect of antenatal care program on the woman who followed the program and those who did not.

Tool validity and reliability:

Content validity of the study was tested by three expertise in the field of community health nursing and two expertise from obstetric department. Faculty of nursing, Fayoum University, The expertise reviewed the tools for clarity, relevance, comprehensiveness, simplicity and modification for certain items was done. The developed tool was tested for reliability on a sample of ten subjects, test-retest revealed that, all items were significant and have a correlation coefficient above the significant level $(r=0.8)$ of the proposed tools was done statistically by crombach (alpha).

Pilot study:

Pilot study was carried out on 10\% (7 women) after excluded of them from the sample, to evaluate the content of tools applicability and identify the estimated time for data collection. The pilot study was consuming about one month from the beginning to the end February 2018. Data gained from the pilot was analyzed and modification was done accordingly. As well the pilot was excluded from the study sample to avoid sample bias and contamination.

Ethical consideration

The agreements for participation of the subjects were taken after the aim of the study was explained to them. Before data collection, the women were informed about the aim of the study and what would be done with the results. They were given the opportunity to refuse to participate and they could withdraw at any stage of the research. Also, they were assured that the information would remain confidential and used for the research purpose only. The researcher gave copies from the developed integrated educational program maternal to women for achieving the educational principles of research as well as the principles of beneficence. The ethics committee approval is in the college of nursing Fayoum University, Egypt on the subject of research. Women's informed consent was obtained to participate in the study after explaining the purpose of the study. Also, confidentiality and privacy were ascertained regarding the data collected. 
Field work:

Official permission to conduct the study was obtained from the responsible authorities through official letters from Faculty of Nursing explaining the purpose of the study to the Ministry of Health administrative authorities in order to obtain their acceptance to collect necessary data from the selected settings. Then, the permission was obtained from the center's administrative authorities. Tools were developed by the researcher after review of the relevant literature in addition to experts' opinion. Data collection lasted six months started from march 2018 to the end of August 2018 and were accomplished in the morning from 9:00a.m. to 1:00p.m. Three times per week according to the identified days of the week for antenatal care at the previously mentioned M.C.H centers.

Limitation of the study:

I attempted to minimize the interviewer bias by employing local community interpreters. A recall bias, especially considering pregnancy intents but also the experience of the most recent birth might have also influenced the study results. Some limitations should be considered when interpreting the findings of present study. One is that our sample size was relatively small. Moreover, most data were self-reported and not validated using objective measures. Interviewer and social desirability biases may also be possible, but are less likely in childbirth-related events compared with other more sensitive issues.

Procedure of data collection:

The educational program was constructed on four phases:

1) Assessment phase: it involved the pre-intervention data collection for baseline assessment. Upon obtaining necessary official permissions to carry out the study, the researcher introduced them self to each participant, who fulfilled the criteria for inclusion explained to them the aim and procedures and invited them to participate in the study. The researcher then read and explained each item of the study tool to the women and recorded her responses to each item. The time consumed for completing the interview and filling in the form ranged from 15 to 30 minutes. The researcher collected the demographic data of the women, women knowledge and practices about educational program. Then the intervention program was designed based on the results of assessment (pre-test and using the interviewing questionnaire and the observation checklists).

2) Planning (preparatory) phase: Based on the results obtained from assessment phase the researcher designed the educational program the objective was to improve women knowledge and practices regarding to obstetric danger signs. The program consisted of four main components supported by pictures. The first component was for giving an introduction about physiological changes of pregnancy the second component focused on obstetric danger signs of pregnancy the third component with danger signs of labor, and the fourth component included danger signs of the perineum.

a) This phase based on outcomes obtained from the assessment phase.

b) The program content and media, posters, and visual materials) were pre- 
pared by the researchers for women under the study based on women learning needs.

c) This program was supplemented using a diversity of teaching methods that included (lecture, discussion, clinical training, case study, and brain storming).

3) The implementation phase: the intervention was implemented in the form of educational sessions. The duration of each 8-session ranged from $20-30 \mathrm{mi}-$ nutes. It was difficult to gather all women at the same time so the program was implemented in small groups in the antenatal clinics, each group consisted of two or three women according to their attendance. All participants received the same content using same training methods and same booklets. The training methods included demonstration, re-demonstration. Discussions, role-play and reinforcement. The sessions were aided by using pictures and posters.

a) The program was implemented for the study group in the previously mentioned setting.

b) The researchers conduct the intervention program after finishing the pre-test in form of questionnaire and observational checklist.

c) The researchers used different audiovisual aids such as: data show (power point), booklet and pictures.

d) The researcher visited $\mathrm{MCH}$ centers in previously mentioned villages. The collection process starting from $9.00 \mathrm{am}$ to $1.00 \mathrm{pm}$ for 3 days weekly, and it was conducted in the meeting room to fill in the questionnaire.

e) Each woman took about 45 minutes to fill in the questionnaire: the researcher took nearby one hour to evaluate women practices for every woman by eye observation.

f) At the beginning of each session, the researcher started by giving a summary about the previous session and explaining the objective of the new one.

The duration of each session ranged from 20 - 30 minutes. Followed by $5-10$ minutes for a summary and conversation of what has been accomplished. The intervention program was covered the following topics (define the meaning of danger signs, mention danger signs during pregnancy, labor and postpartum and maternal and fetal complications:(Miscarriage, Ectopic pregnancy, Molar pregnancy, Placenta previa, Abruption placenta, Preterm labor, Gestational diabetes, Heart disease, Pre-eclampsia, Eclampsia, HELLP syndrome, Hyperemesis gravidarium, Anemia, Hydramnios, RH incompatibility, Gramping contraction, rupture of membranes, absence of fetal movement muscle irritability, persistent vomiting, urine frequency or oliguria, spotting or vaginal bleeding, pain (epigastric, abdominal uterine). Practices to overcome danger signs during current pregnancy (Contact with a doctor, going to hospital, Get more rest, Anticipated practices to overcome any arose danger signs, during labor \& delivery and postpartum period: Consult others (mothers and relatives), Self-care practices (treat myself/self-prescribed medications), Sleep on my back and don't move, Go to hospital, Contact with a doctor. The program composed of 8 separated main sessions ( 4 theories, and 4 practice sessions) for the women. women were ar- 
ranged into group, each contained 2 - 3 women according to the accessible time for them.

4) Follow up was done to the studied group and histopathology assessments of the Product of conception in cases of abortion secondary to the complications to compare between effect of antenatal care program on the woman who followed the program and those who did not.

5) Evaluation phase: Evaluation of the effectiveness of educational program was done immediately after the intervention program using (post-test), through using the same pre-test tools.

Statistical Design: Data entry and statistical analysis were done using the statistical package for social science (SPSS version 22) statistical software package. Cronbach's alpha coefficient was calculated to assess compared using chi-square test. Spearman rank correlation was used for assessment of the interrelationship among quantitative variables and ranked ones. In order to identify the independent predictors of women's knowledge and practices scores. Multiple linear regression analysis was used. Demographic information was summarized using descriptive statistics in the form of frequencies and percentages. The calculated data and percentage distribution, and paired t test to examine the overall changes of the pre-test and post-test scores. One-way a nova was used for mean and standard division. Independent $t$ test was also employed to compare the post-test score. Statistical significance was set at $\mathrm{p}<0.005$. Statistical methods were applied (percentage, chi-square $\left(\mathrm{x}^{2}\right), \mathrm{P}$ value was considered that: non-significant (NS) if $\mathrm{P}>0.05$, significant $(\mathrm{S})$ if $\mathrm{P}<0.05$, Highly significant (HS) if $\mathrm{P}<0.01$.

\section{Results}

There is statistically significant difference between total knowledge score about obstetric danger signs at different times from pre and post educational program of the studied cases. Concerning relations between total mean of knowledge score (pre-intervention) in relation to demographic characteristics of studied women. Indicate that statistically significant positive relations were found with women's age, marital status and occupation. Regarding practices performed by women toward danger signs during current pregnancy, the women $45 \%$ pre -program contact with a doctor, while the women $71.40 \%$ post program contact with a doctor. the women $71.40 \%$ pre-program going to hospital, while the women $94.3 \%$ post program going to hospital, the $65 \%$ ) pre-program get more rest, while of the women $100 \%$ post program get more rest. The anticipated practices to overcome any arose danger signs during labor \& delivery and postpartum period will consult doctors and go to hospital mentioned $60 \%$ and $45.7 \%$, pre-program, while the women $97.1 \%$ and $85.7 \%$ post-program. More the women self-care practices and sleep on my back and don't move pre-program, while all $100 \%$ and $85.7 \%$ post program of the women, respectively. Statistically highly significant differences between total practice score danger signs of obste- 
tric complications pre and post program is detected in Major danger signs during pregnancy include: severe vaginal bleeding, swollen hands/face, and blurred vision. Major danger signs during labor and childbirth include severe vaginal bleeding, prolonged labor ( $>12 \mathrm{~h}$ ), convulsions, and retained placenta. Having knowledge and practices of obstetric danger signs is an essential step in recognizing complications and enables one to take appropriate action to access emergency care [13].

The current study according to socio-demographic characteristics of the women showed that the regarding to their level of education, majority of them were read and write. The current studied showed that more than three quarters of women were aged from 24 to less than 30 years old, regard to marital status most of them married. The more than two third living in living in rural areas, more than half family number 4 - 5. this is in accordance with, Hashem, (2016) conducted a study to assess the awareness and knowledge of pregnancy women precautions in university teaching hospital in Ajman, United Arab Emirates [12].

This is comparable to Mohamed \& Abd El Azize, (2017) an Egyptian study entitled "Quality of life after vaginal and cesarean deliveries among a group of Egyptian women" [14]. The study revealed an age range between $21-40$ years old for their studied women with a mean age of $25.5 \pm 3.80$ years. Besides a high proportion the studied women had at least secondary education, and one-third of them was employed. These similarities allow the comparison of findings between this study and the current study as they study the quality of life at the period of 2 to three months postpartum). Most participants in present study had a relatively high educational status compared to those in other studies in similar low- and middle-income African countries. In present study, most of them read and write and more than one tenth secondary and high education. In contrast, in the study conducted by Hailu and colleagues in Tsegedie district, Ethiopia, more than half of women were unable to read [4]. Educational program in low- and middle-income countries have increased in recent years and most of the interventions used by health care providers in the field of maternal and neonatal health have addressed health education, workflow and disease prevention [15].

Furthermore, in our study the knowledge of danger signs for the four periods showed important variations. This finding is consistent with another studies, the educational status of women varied in the different studies. Higher education status has been associated with increased obstetric awareness. Having secondary education or higher increased the knowledge of danger signs during pregnancy, delivery and the postpartum significantly [14]. Also, working women have better opportunity to share experiences with others than housewives. This discrepancy may be due to difference in perception of the severity of obstetric danger signs among women, knowledge level or difference in cultural background which may affect their practices [2].

As regard to the source of information about danger signs the current study 
findings the radio and T.V more than two fifth and family more than one fifth were the commonest source of information reported by women. The present show that less than two fifth of the reported women that didn't receive any information about obstetric danger signs. The similarity with Kuo, et al. 2016 a study entitled "relationship between health-related quality of life determinants and type of delivery in Saudi women." findings could be justified by had their own experience which is an important source of information [16]. Accordingly, empowering women with information enables them to understand and articulate their health needs and to seek assistance without delay. Failure to give information keeps women "in the dark" and creates a barrier between the consumers and service providers. Therefore, women's empowerment is a key strategy for maternal mortality reduction through danger sign education and early intervention because it provides them with the capacity to make critical decisions about their own health. It also enables them to seek care when they think they need it, follow medical procedures, and participate in health activities and education programs.

The current study As regard to the obstetric and medical history of the women finding that the gravidity three time is less than half and nullipara, more than half delivery in governmental hospital and majority non abortion, attendance of antenatal care it was observed that more than three quarters of women sought initial antenatal visit at first trimester, showed that less than two fifth of women received antenatal care at governmental hospital, more than half of women had more than three antenatal visits during their current pregnancy and more than half the distance between home and antenatal care decrease than one hours. This is in accordance with El-zanaty et al. (2018) in a study entitled (Egypt demography and health survey [17]. It reported that, there was majority the obstetric history of the nulliparous women, normal delivery and governmental hospital was reported place of delivery of women. It was observed the more than three quarters of women sought initial antenatal visit at first trimester and half of the women had than three antenatal visits during their current pregnancy.

The current study According to their attendance of antenatal care finding that was observed that more than three quarters of the women sought initial antenatal visit at first trimester and only few of them had their initial visit at third trimester. The table also showed that majority of the women received antenatal care at Governmental hospital, and Maternal and Child Health centers, while more than one tenth of the women received antenatal care at private hospital and doctor's clinic and only few of them of the women received antenatal care at governmental hospital. The table also illustrated that more than half of the women had more than three times antenatal visits during their current pregnancy, followed by less than one fifth of the women had from 3 - 4 antenatal visits. Show that more than half of women distance between home and antenatal care unit decrease than one hours (Tables 1-6). 
Table 1. Distribution of socio-demographic characteristics of the women.

\begin{tabular}{|c|c|c|}
\hline \multirow{2}{*}{ Socio-demographic data } & \multirow{2}{*}{$\begin{array}{c}\text { Women } \\
\mathrm{N}\end{array}$} & \multirow{2}{*}{$\begin{array}{c}N=70 \\
\%\end{array}$} \\
\hline & & \\
\hline \multicolumn{3}{|l|}{ Age (years): } \\
\hline$<20$ & 8 & 11.4 \\
\hline $20-30$ year & 50 & 71.7 \\
\hline$>30$ year & 12 & 17.1 \\
\hline Range & $18-36$ & \\
\hline Mean \pm SD & $24.6 \pm 4.8$ & \\
\hline \multicolumn{3}{|l|}{ Marital status } \\
\hline Married & 65 & 92.8 \\
\hline Divorced & 5 & 7.1 \\
\hline \multicolumn{3}{|l|}{ Residence: } \\
\hline Urban & 20 & 28.6 \\
\hline Rural & 50 & 71.4 \\
\hline \multicolumn{3}{|l|}{ Educational level: } \\
\hline Read and write & 60 & 85.7 \\
\hline Secondary and high education & 10 & 14.3 \\
\hline \multicolumn{3}{|l|}{ Occupation: } \\
\hline Housewife & 60 & 85.7 \\
\hline Working & 10 & 14.3 \\
\hline \multicolumn{3}{|l|}{ Family number } \\
\hline$\leq 3$ & 28 & 40.0 \\
\hline $4-5$ & 39 & 55.71 \\
\hline $6-7$ & 3 & 4.2 \\
\hline \multicolumn{3}{|l|}{ Socioeconomic status } \\
\hline High & 4 & 5.7 \\
\hline Middle & 6 & 8.6 \\
\hline Low & 60 & 85.7 \\
\hline Total & 70 & 100 \\
\hline
\end{tabular}

Table 1 show that $71.7 \%$ of the studied women their age ranged between $20-30$ years with a mean age 24.6 \pm 4.8 years and $92.8 \%$ of them were married. Additionally, $71.7 \%$ of them living in rural areas. Concerning the educational level of them had Read and write education with low Socioeconomic status. Regarding occupation $85 \%$ of women were housewives.

Table 2. Frequency distribution of studied women according to their source of information about obstetric danger signs.

\begin{tabular}{ccc}
\hline Source of information & Frequency & percent \\
\hline Physician & 3 & 4.2 \\
TV \& radio & 28 & 40.0 \\
Internet & 3 & 4.2 \\
Family & 16 & 22.9 \\
More than one answer & 20 & 28.6 \\
Total & 70 & 100.0 \\
\hline
\end{tabular}

These findings are different as compared with Sangal et al. (2017), who" Knowledge and practices regarding obstetric danger signs in women attending ante-natal care clinic" mentioned that more than half of women consulted a 
Table 3. Frequency of distribution of women according to their obstetrics medical history.

\begin{tabular}{|c|c|c|}
\hline Obstetrical history & \multicolumn{2}{|c|}{ Women $(N=70)$} \\
\hline \multicolumn{3}{|l|}{ Gravidity: } \\
\hline $1-2$ & 30 & 42.86 \\
\hline-3 & 34 & 48.57 \\
\hline$>3$ & 6 & 8.57 \\
\hline \multicolumn{3}{|l|}{ Parity: } \\
\hline Nullipara & 36 & 46.5 \\
\hline $1-2$ & 17 & 27.0 \\
\hline-3 & 16 & 25.5 \\
\hline$>3$ & 1 & 1.0 \\
\hline \multicolumn{3}{|l|}{ Type of last delivery: } \\
\hline Normal & 40 & 57.14 \\
\hline Cesarean section & 30 & 42.85 \\
\hline \multicolumn{3}{|l|}{ Place of previous delivery: } \\
\hline No & 10 & 14.3 \\
\hline Home & 8 & 11.42 \\
\hline Governmental hospital & 32 & 45.71 \\
\hline others & 20 & 28.6 \\
\hline \multicolumn{3}{|l|}{ Number of abortions: } \\
\hline None & 57 & 81.42 \\
\hline $1-2$ & 12 & 17.14 \\
\hline$>2$ & 1 & 1.42 \\
\hline total & 70 & 100 \\
\hline
\end{tabular}

Table 3 demonstrates the distribution of the women according to their obstetrical history. It was observed that gravidity three time $48.57 \%$ were pregnant, while parity $46.5 \%$ of the women were nullipara. As regard to the type of last delivery, the women $57.14 \%$ had normal spontaneous vaginal delivery and the rest of them $42.85 \%$ delivered by cesarean section. The governmental hospital was the most commonly reported place of previous last delivery mentioned by $45.71 \%$ of the women. The women $81.42 \%$ had no history of abortions, while only (1.42\%) had a history of abortions more than two times.

Table 4. Distribution of the women according to their attendance of antenatal care.

\begin{tabular}{ccc}
\hline & \multicolumn{2}{c}{ Women $(\mathbf{N}=70)$} \\
Antenatal care attendance & $\mathbf{n}$ & $\%$ \\
\cline { 2 - 3 } & & \\
Time of the initial visit: & 55 & 78.57 \\
First trimester & 13 & 18.57 \\
Second trimester & 2 & 2.8 \\
Third trimester & & \\
Place of antenatal care: & 58 & 82.85 \\
Governmental hospital & 3 & 4.28 \\
Private hospital/private doctor's clinic & 9 & 12.85 \\
Health centers/MCH & & \\
Number of antenatal visits: & 2 & 2.82 \\
Once & 13 & 18.57 \\
Twice & 36 & 51.43 \\
Three times & 10 & 14.28 \\
Four times & 9 & 12.85 \\
More than four & & \\
\hline
\end{tabular}




\section{Continued}

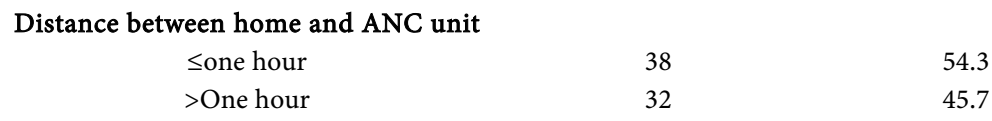

Table 4 illustrates distribution of the women according to their attendance of antenatal care. It was observed that of the women (78.5\%) sought initial antenatal visit at first trimester, also showed that $82.85 \%$ of the women received antenatal care at Governmental hospital, the women $(51.43 \%)$ had more than three antenatal visits during their current pregnancy, followed by $(14.28 \%$, and $18.57 \%$ respectively) of the women had from 3 - 4 antenatal visits. Show that 54.3 of women distance between home and antenatal care unit decrease than one hours.

Table 5. Distribution of women regarding their knowledge before and after the educational programs.

\begin{tabular}{|c|c|c|c|c|c|c|}
\hline \multirow{2}{*}{$\begin{array}{l}\text { Knowledge regarding parameters of } \\
\text { obstetrical complications }\end{array}$} & \multicolumn{2}{|c|}{ Pre program } & \multicolumn{2}{|c|}{ Post program } & \multirow[b]{2}{*}{$\mathrm{X}^{2}$} & \multirow[b]{2}{*}{$P$ value } \\
\hline & $\mathbf{N}$ & $\%$ & $\mathbf{N}$ & $\%$ & & \\
\hline \multicolumn{6}{|l|}{ Define the meaning of danger signs } & \multirow{3}{*}{$\begin{array}{c}<0.0001^{\star *} \\
(\mathrm{HS})\end{array}$} \\
\hline Aware & 20 & $28.6 \%$ & 64 & $91.4 \%$ & 28.810 & \\
\hline Not aware & 50 & $71.4 \%$ & 6 & $8.6 \%$ & & \\
\hline \multicolumn{7}{|l|}{ Mention danger signs during preg- } \\
\hline nancy & & & & & \multirow{3}{*}{21.766} & \multirow{3}{*}{$\begin{array}{c}<0.0001^{\star *} \\
(\mathrm{HS})\end{array}$} \\
\hline Aware & 4 & 5.7 & 64 & 91.4 & & \\
\hline Not aware & 66 & 94.3 & 6 & 8.6 & & \\
\hline \multicolumn{7}{|l|}{ Mention danger signs during labor and } \\
\hline postpartum & & & & & \multirow{3}{*}{025.963} & \multirow{3}{*}{$\begin{array}{c}<0.0001^{\star *} \\
(\mathrm{HS})\end{array}$} \\
\hline Aware & 20 & 34.3 & 62 & 88.6 & & \\
\hline Not aware & 50 & 65.7 & 8 & 11.4 & & \\
\hline \multicolumn{7}{|l|}{ Miscarriage (Postpartum } \\
\hline hemorrhage and vaginal bleeding) & & & & & \multirow{3}{*}{11.667} & \multirow{3}{*}{$0.0006^{*}$} \\
\hline Aware & 14 & 20.0 & 70 & 100 & & \\
\hline Not aware & 56 & 80 & 0 & 0 & & \\
\hline \multicolumn{7}{|l|}{ Pre-eclampsia and Eclampsia } \\
\hline Aware & 20 & 28.6 & 68 & 97.1 & \multirow[t]{2}{*}{5.081} & \multirow[t]{2}{*}{$0.0242^{\star}$} \\
\hline Not aware & 50 & 71.4 & 2 & 2.9 & & \\
\hline \multicolumn{7}{|l|}{ Gramping contractions } \\
\hline and rupture membranes & & & & & \multirow{3}{*}{11.993} & \multirow{3}{*}{$0.0005^{\star}$} \\
\hline Aware & 30 & 42.9 & 58 & 82.9 & & \\
\hline Not aware & 40 & 57.1 & 12 & 17.1 & & \\
\hline \multicolumn{7}{|l|}{ Puerperal infection and Anemia } \\
\hline Aware & 20 & 28.6 & 64 & 91.4 & \multirow[t]{2}{*}{28.810} & \multirow[t]{2}{*}{$<0.0001^{\star *}$} \\
\hline Not aware & 50 & 71.4 & 6 & 8.6 & & \\
\hline \multicolumn{7}{|l|}{ Placenta previa and } \\
\hline vaginal bleeding pain & & & & & \multirow{3}{*}{23.333} & $<0.0001^{\star *}$ \\
\hline Aware & 20 & 28.6 & 64 & 91.4 & & (HS) \\
\hline Not aware & 50 & 71.4 & 6 & 8.6 & & \\
\hline Preterm labor and RH incompatibility: & & & & & & \\
\hline Aware & 14 & 20.0 & 64 & $91.4 \%$ & 28.810 & $<0.0001^{* x}$ \\
\hline Not aware & 56 & 80 & 6 & $8.6 \%$ & & \\
\hline Hydramnios & & & & & & \\
\hline Aware & 20 & 28.6 & 64 & 91.4 & 23.333 & $<0.0001^{* x}$ \\
\hline Not aware & 50 & 71.4 & 6 & 8.6 & & \\
\hline
\end{tabular}

*Significant $(\mathrm{P}<0.05) * *$ highly significant $(\mathrm{NS})$ not significant. Table 5 show that differences between preand post-educational program in their knowledge regarding obstetrical danger signs during pregnancy and labor finding highly significant between pre and post educational program. 
Table 6. Distribution of the women according to their knowledge regarding fetal complication during pregnancy pre/post educational program.

\begin{tabular}{|c|c|c|c|c|c|c|}
\hline \multirow{3}{*}{$\begin{array}{l}\text { Knowledge regarding fetal } \\
\text { complications during pregnancy: }\end{array}$} & & & & & & \\
\hline & \multicolumn{2}{|c|}{ Pre program } & \multicolumn{2}{|c|}{ Post program } & \multirow{2}{*}{$\mathrm{X}^{2}$} & \multirow{2}{*}{$P$ value } \\
\hline & $\mathbf{N}$ & $\%$ & $\mathbf{N}$ & $\%$ & & \\
\hline \multicolumn{6}{|l|}{ UFD, Congenital malformations. } & \multirow{3}{*}{$\begin{array}{l}<0.0001^{\star *} \\
(\mathrm{HS})\end{array}$} \\
\hline Aware & 30 & $42.9 \%$ & 66 & $94.3 \%$ & 21.477 & \\
\hline Not aware & 40 & 57.1 & 4 & 5.7 & & \\
\hline \multicolumn{6}{|l|}{ absence of fetal movement. } & \multirow{3}{*}{$\begin{array}{c}<0.0001^{* *} \\
(\mathrm{HS})\end{array}$} \\
\hline Aware & 20 & $28.6 \%$ & 60 & $85.7 \%$ & 23.333 & \\
\hline Not aware & 50 & 71.4 & 10 & 14.3 & & \\
\hline \multicolumn{7}{|l|}{ Premature rupture of membranes, } \\
\hline Intrauterine infection & & & & & 5081 & \multirow{3}{*}{$\begin{array}{l}0.0242^{\star} \\
(S)\end{array}$} \\
\hline Aware & 20 & 28.6 & 68 & 97.1 & 5.081 & \\
\hline Not aware & 50 & 71.4 & 2 & 2.9 & & \\
\hline \multicolumn{7}{|l|}{ Post term pregnancy and Rupture } \\
\hline uterus & & & & & \multirow{3}{*}{28.810} & \multirow{3}{*}{$\begin{array}{c}<0.0001^{\star *} \\
(\mathrm{HS})\end{array}$} \\
\hline Aware & 8 & 11.4 & 64 & 91.4 & & \\
\hline Not aware & 62 & 88.6 & 6 & 8.6 & & \\
\hline \multicolumn{6}{|l|}{ Cephalopelvic disproportion, } & \multirow{3}{*}{$\begin{array}{l}0.0242^{\star} \\
(\mathrm{S})\end{array}$} \\
\hline Aware & 14 & 20.0 & 68 & 97.1 & 5.081 & \\
\hline Not aware & 56 & 80.0 & 2 & 2.9 & & \\
\hline \multicolumn{6}{|l|}{ IUGR, Small-for-gestational age. } & \multirow{3}{*}{$\begin{array}{l}0.0005^{*} \\
(S)\end{array}$} \\
\hline Aware & 30 & 42.9 & 58 & 82.9 & 11.993 & \\
\hline Not aware & 40 & 57.1 & 12 & 17.1 & & \\
\hline \multicolumn{6}{|l|}{ Prolapsed umbilical cord. } & \multirow{3}{*}{$\begin{array}{l}0.0005^{*} \\
(S)\end{array}$} \\
\hline Aware & 30 & $42.9 \%$ & 58 & 82.9 & 11.993 & \\
\hline Not aware & 40 & 57.1 & 12 & 17.1 & & \\
\hline \multicolumn{6}{|l|}{ Fetal distress and Still birth } & \multirow{3}{*}{$\begin{array}{l}<0.0001^{* *} \\
\quad(\mathrm{HS})\end{array}$} \\
\hline Aware & 20 & 28.6 & 64 & 91.4 & 28.810 & \\
\hline Not aware & 50 & 71.4 & 6 & 8.6 & & \\
\hline \multicolumn{7}{|l|}{ Respiratory distress syndrome and } \\
\hline \multicolumn{5}{|l|}{ Congenital malformation } & \multirow{3}{*}{21.766} & \multirow{3}{*}{$\begin{array}{c}<0.0001^{\star *} \\
(\mathrm{HS})\end{array}$} \\
\hline Aware & 24 & $34.3 \%$ & 62 & 88.6 & & \\
\hline Not aware & 46 & 65.7 & 8 & 11.4 & & \\
\hline
\end{tabular}

Table 6 show that differences between pre- and post-educational program in their knowledge regarding obstetrical danger signs during fetal complication finding highly significant between pre and post educational program.

health worker/doctor, and approximately three-quarters of women didn't have any consultation despite knowing their danger signs [13]. Even if in a recent review the mixed results exploring the relationship of ANC visits on contraceptive uptake in the first year postpartum have been highlighted, it has been mentioned as well that some studies conducted in Kenya and South Africa have shown an increased uptake of contraceptive methods in the first year postpartum when counseling during ANC visits was provided. Another justification provided by Pembe et al. (2018) Rural Tanzanian women's awareness of danger signs of obstetric complications, who reported as nearly all participants at least one ANC 
visit, ANC provides a unique opportunity to educate women about obstetric danger signs [15]. Whereas; early initiation of antenatal care provides women with an excellent opportunity for information and early detection of any complications or risk factors. The challenges to providing quality ANC should be considered in current and future programs, including the important role that a Health application may have on these services.

Similar findings reported by Ahmed, et al. [5] studied Ramification of complications occurring during pregnancy who important point of consideration is, given the high attendance at the ANC visits, whether family planning counseling should be included in the ANC visits in hospital. As previously noted, nearly all women in current study had benefited from ANC during their pregnancy and more than two thirds had even attended the WHO-recommended four regular ANC visits. Furthermore, we believe that the women reached in studied were in general those who had a more positive attitude towards the health system.

These results could be explained according to Gupta (2016) Maternal mortality: Magnitude causes and concerns, who stated that slightly more than one quarter of Egyptian pregnant women didn't receive antenatal care. However, among those who receive antenatal care only one third of them received minimal information about danger signs of obstetric complications and where and when to seek medical assistance [18].

According to presence of obstetric Danger signs during pregnancy, labor and fetal complication: the study finding miscarriage, vaginal bleeding and postpartum hemorrhage are more common in pregnancy and labor complication and more than half intrauterine fetal death in fetal complication, it also agreement with El-Gharib et al. (2015), Causes of maternal deaths in Tanta University Hospital, which estimated that, in Egypt, $42 \%$ of women with pregnancy For every woman who dies from causes related to pregnancy, an estimated 20 to 30 encounter serious complications. At least 15 per cent of all births are complicated by a potentially fatal condition [8].

This is also in contrast with Mohamed \& Abd El Azize, (2017) to other studies in which the most common mentioned danger sign during pregnancy was vaginal bleeding, Severe vaginal bleeding was also the most common mentioned danger sign during pregnancy in the studies [14]. A possible explanation for this difference might the positive effect of a public health campaign for the prevention of preeclampsia recently. The campaign highlighted the danger signs for preeclampsia during pregnancy and didn't mention explicitly danger signs during childbirth, in the postpartum or in the newborn. This could explain the lower knowledge of danger signs among women during those periods.

Similar findings reported by Khanum, et al., 2017. Finding that at least $20 \%$ of maternal deaths occur due to complications during delivery and the immediate postpartum period (such as hemorrhage or infection), information about postpartum problems is essential to save mother's [19]. Also, the knowledge of danger signs in the newborn was lower in our study than in other studies conducted in Africa Madagascar's newborn mortality rate remains high and early detection 
of neonatal illness to improve newborn survival is urgently needed.

Essentially, all women in developing countries are at risk of obstetric complications. These complications are virtually inconceivable to anticipate and hard to forestall. Medical and nursing management for women with obstetric complications begins with the recognition of danger signs. Because lack of knowledge about danger signs of obstetric complications often delays decision-making for health care service seeking, resulting in tragic consequences, where women die at home or in their way to the health facility

According to result finding their knowledge regarding obstetrical danger signs during pregnancy, labor and fetal complication pre/ post educational program): the current study finding according to research hypothesis the findings of the current study also revealed that only very few women exhibited good knowledge about obstetric danger signs But post program majority had knowledge of obstetrical complications that may occur during pregnancy, labor, and puerperium, while only less than one fifth had no knowledge. It was observed that miscarriage, bleeding, and postpartum hemorrhage were the most commonly known complications by more than one third and more than one fifth of the women. Despite the variations in the knowledge about danger signs during the different periods, which are consistent with current studies, we noted important discrepancies in respect to the period of pregnancy or childbirth in which women were most knowledgeable. In current study, more than three quarter of women knew at least one danger sign during pregnancy, which is similar to Mohamed \& Abd El Azize, (2017) impact of gestational diabetes mellitus on health quality of life in Egypt a study conducted in Egypt, where more than two fifth out of 394 women new at least one danger sign during pregnancy [14].

In current study it was knowledge of obstetrical complications aware preprogram less than one third but aware post-program most of them aware highly significant between pre- and post-program. In the studies agree with Hashem, (2016) A study to assess the quality of immediate postpartum nursing care provided to women after cesarean section in Tanta City, the knowledge of at least two fifth danger signs were low during pre-educational program, while post program most of them knowledgeable for danger signs during pregnancy. As the provision of family planning reduces maternal deaths due to unsafe abortions and spacing of pregnancies can improve the survival chances and health outcomes of women and newborn, we consider the inclusion of family planning into ANC as important to consider in our setting [12].

According to their practices regarding danger signs of obstetric complications pre and post educational program According to research hypothesis practices performed by women toward danger signs during current pregnancy, the less than half of the women pre -program contact with a doctor, while less than two fifth of the women post program contact with a doctor. The less than two fifth of the women pre-program going to hospital, while majority of the women post program going to hospital, the less than two fifth pre-program get more rest, 
while all of them of the women post program get more rest.

The anticipated practices to overcome any arose danger signs during labor\& delivery and postpartum period will consult doctors and go to hospital mentioned by more than half and less than half pre-program, while majority of the women and most of them post-program. More than half of the women self-care practices and sleep on my back and don't move pre-program, while all of them and most of them post program of the women. The findings of educational program that was confirming the research hypotheses and executed that there was significant improvement of knowledge and practices regarding educational program these results are line with "Barriers to emergency obstetric care services in perinatal deaths in Rural Gambia" who stressed that suggested educational program is effective in improving women knowledge and practices [20]. In contrast to our findings, in the study conducted in Fayoum the knowledge of at least one danger sign was best during childbirth and the postpartum, while in the study in Tanzania, women were most knowledgeable for danger signs after delivery [14].

Relation between total Mean of knowledge score (pre-educational) in relation to Demographic studied women. Concerning relations between total mean of knowledge score (pre-intervention) in relation to demographic characteristics of studied women. Indicate that statistically significant positive relations were found with women's age, marital status and occupation.

This is difference with Mohamed \& Abd El Azize, (2017), in a study entitled (impact of gestational diabetes mellitus on health quality of life in Egypt). It reported that, there was no statistically significant difference between the experimental and the control group regarding their sociodemographic characteristics in terms of age, residence and socioeconomic level they are almost matching. It reported that, there was statistically significant regarding their socio-demographic characteristics in terms of age, residence and socioeconomic level, they are almost matching [14].

Difference of total knowledge score regarding obstetric danger signs of pre and post health educational program: According to research hypothesis in the study we observed a synergistic effect of education. The study agree according to research hypotheses who have previously stated that educated women might have better access to knowledge and practices that education facilitates the understanding of health information and improves autonomy in health decisionmaking statistically significant difference between total knowledge score about obstetric danger signs at different times from pre and post educational program of the studied. These results are similar with Rashad and Essa (2017) in a study entitled (Women's awareness of danger signs of obstetrics complications [21]. It stressed that suggested training program is effective in improving women knowledge about danger signs should be provided and health campaign influenced positively on the women the knowledge and practices about danger signs of complication.

This finding is in agreement with Kabakyenga et al. (2015) in a study entitled 
(Knowledge of obstetric danger signs and birth preparedness practices among women in rural Uganda [22]. It reported that the low levels of knowledge of obstetric danger signs of women without increase adherence to educational program was primary due to increases of knowledge. This corresponds with Khalil, (2016) in a study entitled assess knowledge and awareness about the complication of pregnancy women. It mentioned that only one quarter of their study subjects exhibited good knowledge about obstetric danger signs. My opinion Knowledge of obstetric danger signs is important to shape health seeking behaviors which contribute to save women's life that stressed.

The present study according to their total practice score regarding the danger signs of obstetric complications pre/post educational program finding according to research hypotheses show that statistically highly significant differences between total practice score danger signs of obstetric complications pre and post program. The similarity the previous studies Bimala (2017), in a study entitled (An exploratory study of prevailing, knowledge, attitude and practice of husband in regards to factors affecting in supporting activities during pregnancy). It reported that also indicated that most of the respondents had visited health facility when they had danger signs, while slightly more than one tenth either had contact with health personnel or did nothing during such conditions. The risk of adverse prenatal outcome goes down as the length of education increases, due to women's ability to follow instructions, start prenatal care early, and attend more visits [23].

On the other hand, if these danger signs appeared during labor/delivery and postpartum period, the current study revealed that less than half of women mentioned they will consult a doctor. These findings disagree with a result carried out by Mutiso et al. (2018), in the study entitled (Birth preparedness among antenatal clients). It reported that noticed that the majority of their respondents would seek urgent medical consultation in case of an emergency as opposed to one tenth who would either pray or didn't know what to do [24].

Correlation between total practice and their knowledge about danger signs of obstetric complications of the women. Show that the findings of the present study revealed that about two thirds of the women exhibited poor knowledge and practices regarding obstetric danger signs pre-educational program but post -educational program become high knowledge and practice. According the research hypotheses the study finding statistically significant difference between total practices and total knowledge pre and post program. These results are in agreement with Raoof \& AlHadithi (2017) in a study entitled (Antenatal care in Erbil City-Iraq). It reported that a statistically significant correlation was present between knowledge and practices of obstetric danger [25]. This study therefore aimed to evaluate the current status of knowledge and practices of pregnant women toward danger signs of obstetric complications. Concerning the overall knowledge and practices total score level regarding obstetric danger signs (Figures $1-3)$. 


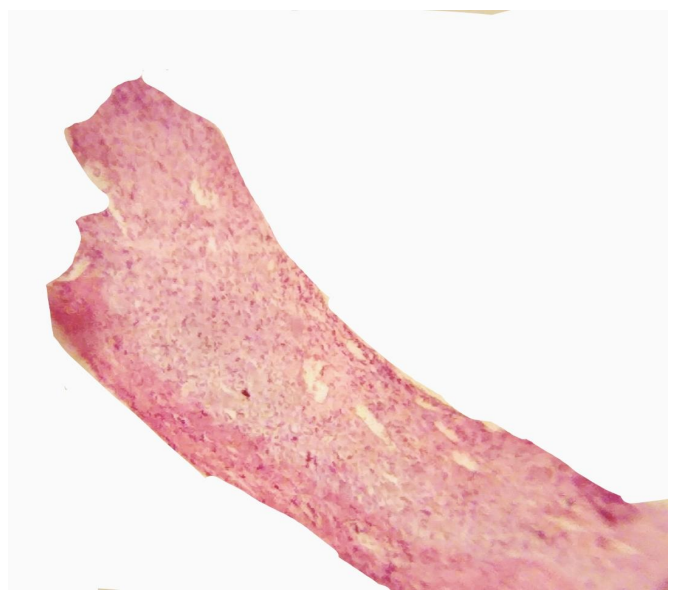

Figure 1. Microscopic picture of chorioamnionitis showing inflamed chronic membranes and infiltration by inflammatory cells $(\times 100, \mathrm{H} \& \mathrm{E})$.

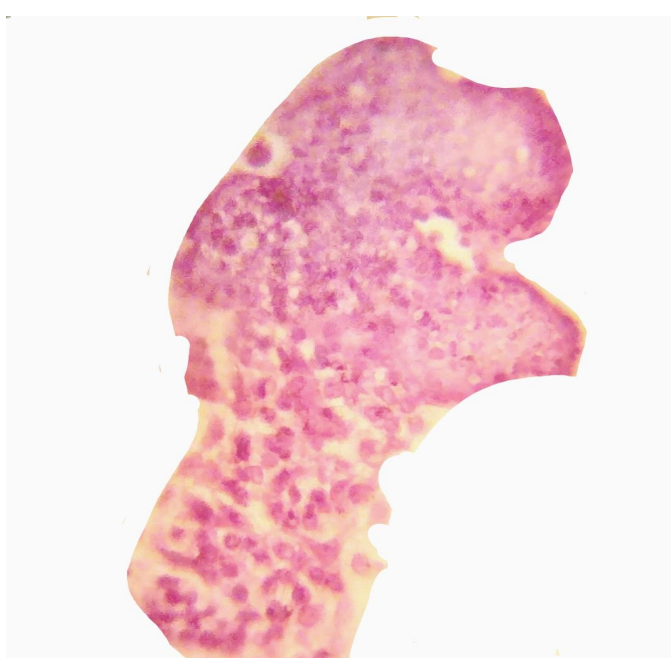

Figure 2. Microscopic picture of decidual cast with infiltration of decidua by inflammatory cells $(\times 100, \mathrm{H} \& \mathrm{E})$.

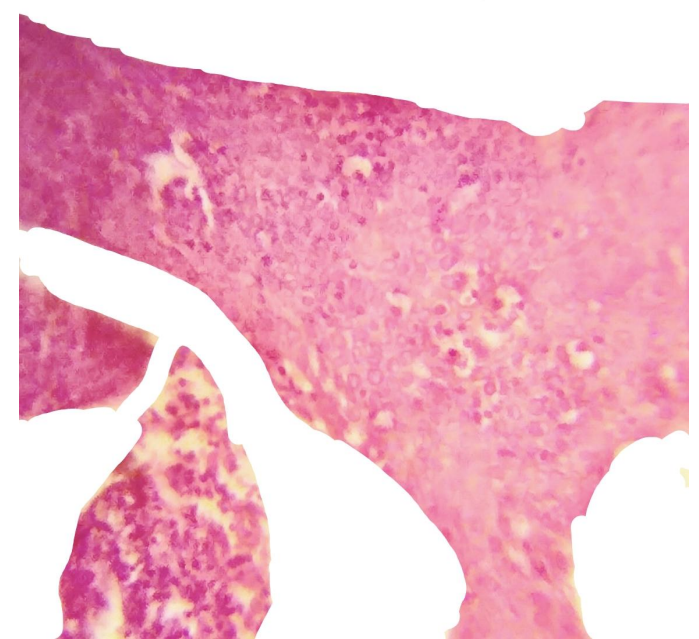

Figure 3. Microscopic picture of chorioamnionitis showing inflamed chrionic membranes and infiltration by inflammatory cells $(\times 100, \mathrm{H} \& \mathrm{E})$. 


\section{Conclusions}

According to the result finding, research hypothesis is justified as the educational program was effective in increasing women's total knowledge and practices score about obstetric danger signs. Before implementation of educational program women in ANC clinics have low score of knowledge and practices about obstetrics danger signs while after implementation of educational program high score of knowledge and practices.

The relation between knowledge and practices was reported regarding danger signs of obstetric complications among pregnant women pre educational program and post educational highly significant. According to the actual practices taken by women to overcome their danger signs during current pregnancy, consult doctor was the actual mentioned practice by women during current pregnancy and it was also the anticipated practice during labor/delivery and postpartum period. A significant correlation was found between women's level of education, occupation, age, time of the initial antenatal visit and their knowledge about obstetric danger signs. Histopathology assessment confirmed the same most common causes of pregnancy loss in all patients and, which can be avoided using the educational care program to raise awareness about the importance of antenatal care and warning signs of Obstetrics complications which could possibly prevent an expected complication and improve the pregnancy outcome through regular follow up.

\section{Recommendations}

- The study found that women at the ANC clinics should have education about danger signs. Future research is needed to identify creative and innovative ways to educate pregnant women about danger signs and in facilitating uptake of delivery services developing antenatal classes for all pregnant women about obstetric danger signs and the proper time to seek medical care.

- In addition, the booklet should be utilized and community organizations mobilized to disseminate correct and relevant information about danger signs of obstetric complications to women, families and communities.

- Further studies are needed in this field to assess the effect of health education program on women's knowledge and practices regarding obstetric danger signs during pregnancy, labor and postpartum period.

- Histopathological assessment for the products of conception proved to be an important tool in detecting causes of pregnancy related complications that necessitate special follow-up protocol and unmasking causes of abortion for further management. And histopathology confirmed that women especially high risk who followed regular antenatal programs with continuous visits were able to avoid presumed complications as Preeclampsia and other danger signs.

\section{Conflicts of Interest}

The authors declare no conflicts of interest regarding the publication of this paper. 


\section{References}

[1] Hasan, I. and Nisar, N. (2002) Women's Perceptions Regarding Obstetric Complications and Care in a Poor Fishing Community in Karachi. Journal of Pakistan Medical Association, 52, 148-152.

[2] Acharya, T.K. and Poudel, M. (2016) Knowledge Regarding Obstetrics Danger Signs among Antenatal Mothers Attending a Tertiary Level Hospital. International Journal of Nursing Research and Practice, 3, 31-40.

[3] Agus, Y. and Horiuchi, S. (2012) Factors Influencing the Use of Antenatal Care in Rural West Sumatra, Indonesia. BMC Pregnancy and Childbirth, 12, Article No. 9. https://doi.org/10.1186/1471-2393-12-9

[4] Hailu, M., Gebremariam, A. and Alemseged, F. (2010) Knowledge about Obstetric Danger Signs among Pregnant Women in Aleta Wondo District, Sidama Zone, Southern Ethiopia. Ethiopian Journal of Health Science, 20, 25-32. https://doi.org/10.4314/ejhs.v20i1.69428

[5] Ahmed, A., Chaudhry, A., Hussain, S., et al. (2017) Ramification of Complications Occurring during Pregnancy. Science International (Lahore) Journal, 25, 119-122.

[6] Gebrehiwot, H., Bahta, S. and Haile, N. (2014) Awareness of Danger Signs of Pregnancy and Its Associated Factors among Pregnant Women Who Visit ANC in Mekelle Public Hospitals. American Journal of Advanced Drug Delivery, 2, 164-173.

[7] Abas, A. and Fakhredeen, A. (2017) Knowledge about Danger Signs and Symptoms of Pregnant Women Attending Care Centers in Baghdad City. IOSR Journal of Nursing and Health Science, 6, 37-40. https://doi.org/10.9790/1959-0604023740

[8] El-Gharib, M., Rakha, S., Awara, A., et al. (2010) Causes of Maternal Deaths in Tanta University Hospital. Clinical Medicine Reviews in Women's Health Journal, 2, 79-83. https://doi.org/10.4137/CMRWH.S5907

[9] Doctor, H., Findley, S., Cometto, G., et al. (2013) Awareness of Critical Danger Signs of Pregnancy and Delivery, Preparations for Delivery and Utilization of Skilled Birth Attendants in Nigeria. Journal of Health Care for the Poor and Underserved, 24, 152-170. https://doi.org/10.1353/hpu.2013.0032

[10] Tamrakar, A. (2017) A Study to Evaluate the Effectiveness of Planned Teaching Program on Knowledge of Primigravida Regarding Selected Aspects of Safe Motherhood in Selected Hospitals. Master Thesis, Rajiv Gandhi University of Health Sciences, Pavan College of Nursing, Bangalore.

[11] John, D. and Catherine, T. (2005) Guidelines for Pregnancy Care and Management of Common Obstetric Complications by Medical Officers. Tripuranrhm.gov.in. 2021. http://tripuranrhm.gov.in/Guidlines/Pregnancy Care.pdf

[12] Hashem, S. (2012) A Study to Assess the Quality of Immediate Postpartum Nursing Care Provided to Women after Cesarean Section in Tanta City. Master Thesis, Tanta University, Faculty of Nursing, Tanta.

[13] Sangal, R., Srivastava, R., Singh, A., et al. (2012) Knowledge and Practices Regarding Obstetric Danger Signs in Women Attending Ante-Natal Care Clinic at Baba Raghav Das Medical College, Gorakhpur. Indian Journal of Preventive and Social Medicine, 43, 11-18.

[14] Mohamed and Abd Elazize (2017) Impact of Gestational Diabetes Mellitus on Health Quality of Life in Egypt and Improving Skilled Attendance at Delivery: A Preliminary Report of the Safe Strategy Development Tool. Birth, 30, 227. https://doi.org/10.1046/j.1523-536X.2003.00252.x

[15] Pembe, A., Urassa, D., Carlstedt, A., et al. (2009) Rural Tanzanian Women's Aware- 
ness of Danger Signs of Obstetric Complications. BMC Pregnancy and Childbirth, 9, 12. https://doi.org/10.1186/1471-2393-9-12

[16] Kuo, C.-Y. (2006) Community Awareness of Maternal and Perinatal Danger Signs in Rural Haiti. UCHC Graduate School Masters Theses 2003-2010.

https://opencommons.uconn.edu/uchcgs masters/85

[17] El-Zanaty, F. and Way, A. (2014) Egypt Health Demography-Health Survey 2017. Ministry of Health and Population and ICF International, Cairo. http://www.measuredhs.com

[18] Gupta, N. (2004) Maternal Mortality: Magnitude Causes and Concerns. Journal of Obstetrics and Gynaecology Today, 9, 555-558.

[19] Khanam, R., Ahmed, S., Creanga, A., Begum, N., Koffi, A., Mahmud, A., Rosen, H. and Baqui, A. (2017) Antepartum Complications and Perinatal Mortality in Rural Bangladesh. BMC Pregnancy and Childbirth, 17, Article No. 81. https://doi.org/10.1186/s12884-017-1264-1

[20] Jammeh, A., Sundby, J. and Vangen, S. (2011) Barriers to Emergency Obstetric Care Services in Perinatal Deaths in Rural Gambia: A Qualitative In-Depth Interview Study. International Scholarly Research Notices, 2011, Article ID: 981096. https://doi.org/10.5402/2011/981096

[21] Rashad, W. and Essa, R. (2010) Women's Awareness of Danger Signs of Obstetrics Complications. Journal of American Science, 6, 1299-1306.

[22] Kabakyenga, J., Ostergren, P., Turyakira, E., et al. (2011) Knowledge of Obstetric Danger Signs and Birth Preparedness Practices among Women in Rural Uganda. Reproductive Health, 8, Article No. 33. https://doi.org/10.1186/1742-4755-8-33

[23] Bimala, B. (2012) An Exploratory Study of Prevailing, Knowledge, Attitude and Practice of Husband in Regards to Factors Affecting in Supporting Activities during Pregnancy, Delivery and Post-Partum Periods. Journal of Nobel Medical College, 1, 45-52. https://doi.org/10.3126/jonmc.v1i1.7287

[24] Mutiso, S., Qureshi, Z. and Kinuthia, J. (2008) Birth Preparedness among Antenatal Clients. East African Medical Journal, 85, 275-283. https://doi.org/10.4314/eamj.v85i6.9625

[25] Raoof, A. and Al-Hadithi, T. (2011) Antenatal Care in Erbil City-Iraq: Assessment of Information, Education and Communication Strategy. Duhok Medical Journal, 5, 31-40. 